\title{
An empirical bracketed duration relation for stable continental regions of North America
}

\author{
Jongwon Lee*1 and Russell A. Green ${ }^{2}$ \\ ${ }^{1}$ Paul C. Rizzo Associates, Inc., Pittsburgh, PA, USA \\ ${ }^{2}$ Department of Civil and Environmental Engineering, Virginia Tech, Blacksburg, VA, USA \\ (Received August 27, 2010, Revised May 20, 2011, Accepted May 30, 2011)
}

\begin{abstract}
An empirical predictive relationship correlating bracketed duration to earthquake magnitude, site-to-source distance, and local site conditions (i.e. rock vs. stiff soil) for stable continental regions of North America is presented herein. The correlation was developed from data from 620 horizontal motions for central and eastern North America (CENA), consisting of 28 recorded motions and 592 scaled motions. The bracketed duration data was comprised of nonzero and zero durations. The non-linear mixed-effects regression technique was used to fit a predictive model to the nonzero duration data. To account for the zero duration data, logistic regression was conducted to model the probability of zero duration occurrences. Then, the probability models were applied as weighting functions to the NLME regression results. Comparing the bracketed durations for CENA motions with those from active shallow crustal regions (e.g. western North America: WNA), the motions in CENA have longer bracketed durations than those in the WNA. Especially for larger magnitudes at far distances, the bracketed durations in CENA tend to be significantly longer than those in WNA.
\end{abstract}

Keywords: bracketed duration; central/eastern North America ground motions; ground motion attenuation; ground motion predictive relationships; stable continental region ground motions; strong ground motion durations

\section{Introduction}

The objective of the study presented herein is the development of an empirical relationship correlating bracketed duration to earthquake magnitude, site-to-source distance, and local site conditions (i.e. rock vs. stiff soil) for stable continental regions of North America (i.e. central/ eastern North America: CENA). Strong ground motion duration is an important parameter for seismic risk assessment because it, along with the amplitude and frequency content of the ground motions, can potentially influence the response of geotechnical and structural systems. For example, when the non-linear behavior (i.e. degradation of stiffness) of a system is considered, strong motion duration greatly affects the amount of damage that will occur (e.g. Bommer and Martinez-Pereira 1999). In this vein, various definitions of strong motion duration have been proposed for quantifying the strong motion phase of ground shakings, which is the portion of the motion that is of engineering interest.

\footnotetext{
* Corresponding author, Ph.D., E-mail: jongwon.lee@rizzoassoc.com
} 
One of the most common ways to quantify strong ground motion duration in engineering practice is bracketed duration $\left(D_{\text {bracket }}\right)$. Bracketed duration is defined as the time interval between the first and last exceedance of ground acceleration above or below a threshold acceleration. Commonly, the threshold acceleration is $+/-0.05 \mathrm{~g}$ (e.g. Bolt 1973, Hays 1975, Page et al. 1972), which is the value used in this study. An example of how bracketed duration is determined is shown in Fig. 1. As may be surmised from this figure, it is possible for a ground motion to have zero-duration if the peak ground acceleration (PGA) of the motion is less than the specified threshold.

The empirical relationship presented herein correlates bracketed duration with earthquake magnitude, site-to-source distance, and local site conditions (i.e. rock vs. stiff soil) for CENA; to the authors' knowledge, this is the first such relationship to be proposed for stable continental motions. The authors also present a similarly developed relationship for active shallow crustal regions (e.g. western North America: WNA). This latter relationship was developed so that comparisons in ground motion duration for the two regions could be made. While there are existing relationships for bracketed duration for WNA, the authors felt that to avoid issues related to differences in duration due to disparities in database size, analysis techniques, etc. that consistently developed relationships for the two regions were needed to make valid comparisons. The correlations were developed by performing non-linear mixed-effects (NLME) regression analyses on data derived from 648 horizontal motion recordings for active shallow crustal regions, and 620 horizontal motions for CENA. The latter ground motion dataset was comprised of both recorded motions and scaled motions and is discussed in more detail later in the paper.

In this paper, the strong ground motion dataset used in this study is described first. Then, basic concepts of the NLME regression method are reviewed, and an approach for incorporating the effects of zero-durations in the predictive model is presented. Next, the proposed functional form of the predictive model is introduced along with the results of the regression analyses, and a

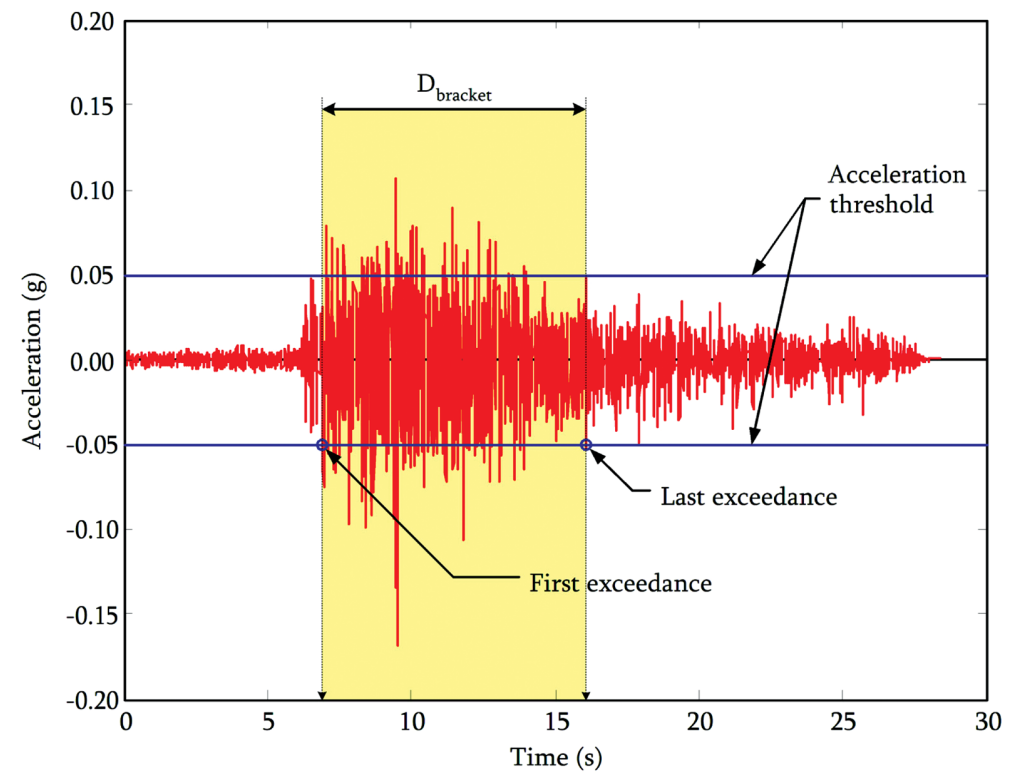

Fig. $10.05 \mathrm{~g}$ bracketed duration for the 1988 Saguenay 1125S17L accelerogram (Magnitude 5.9; site-to-source distance of $70.3 \mathrm{~km}$ ) 
comparison of bracketed durations in CENA and active shallow crustal regions is presented. In addition, a comparison of the proposed and existing relationships is presented next. The scaling procedure used to develop many of the CENA motions is summarized in the Appendix. Finally, it is noted that the acronyms "CENA" and "WNA" in this paper are used to refer to "stable continental" and "active shallow crustal" regions of North America, respectively.

\section{Strong ground motion data}

In total, 648 horizontal earthquake motions from WNA and 620 horizontal motions for CENA were used to develop the empirical relationships. The ground motion dataset was assembled by McGuire et al. (2001). Primarily, this dataset was intended to provide a library of strong ground motion time histories suitable for engineering analyses. The strong motion data for WNA were from 49 earthquakes, with the 1999 Chi-Chi earthquake being the most recent event. The moment magnitudes of these events range from 5.0 to 7.6, and the site-to-source distances range from $0.1 \mathrm{~km}$ to $199.1 \mathrm{~km}$, where site-to-source distance is defined as the closest distance to the fault rupture plane. Because there are few recorded strong ground motions in stable continental regions, only 28 of the motions in the dataset are recorded motions, with the remaining 592 motions being "scaled" WNA motions for CENA conditions. A brief summary of the scaling procedure is provided in the Appendix. The moment magnitudes for these motions range from 4.5 to 7.6, and the site-to-source distances range from $0.1 \mathrm{~km}$ to $199.1 \mathrm{~km}$. The recorded motions include the 1988 Saguenay (main shock $M_{w} 5.9$ and aftershock $\left.M_{w} 4.5\right)$, the 1985 Nahanni $\left(M_{w} 6.8\right)$, and the 1989 New Madrid, MO ( $M_{w}$ 4.7) earthquakes. Fig. 2 shows the magnitude and site-to-source distance distributions for both regions.

McGuire et al. (2001) scaled the WNA motions for CENA conditions using response spectral transfer functions generated from the single-corner frequency point source model along with
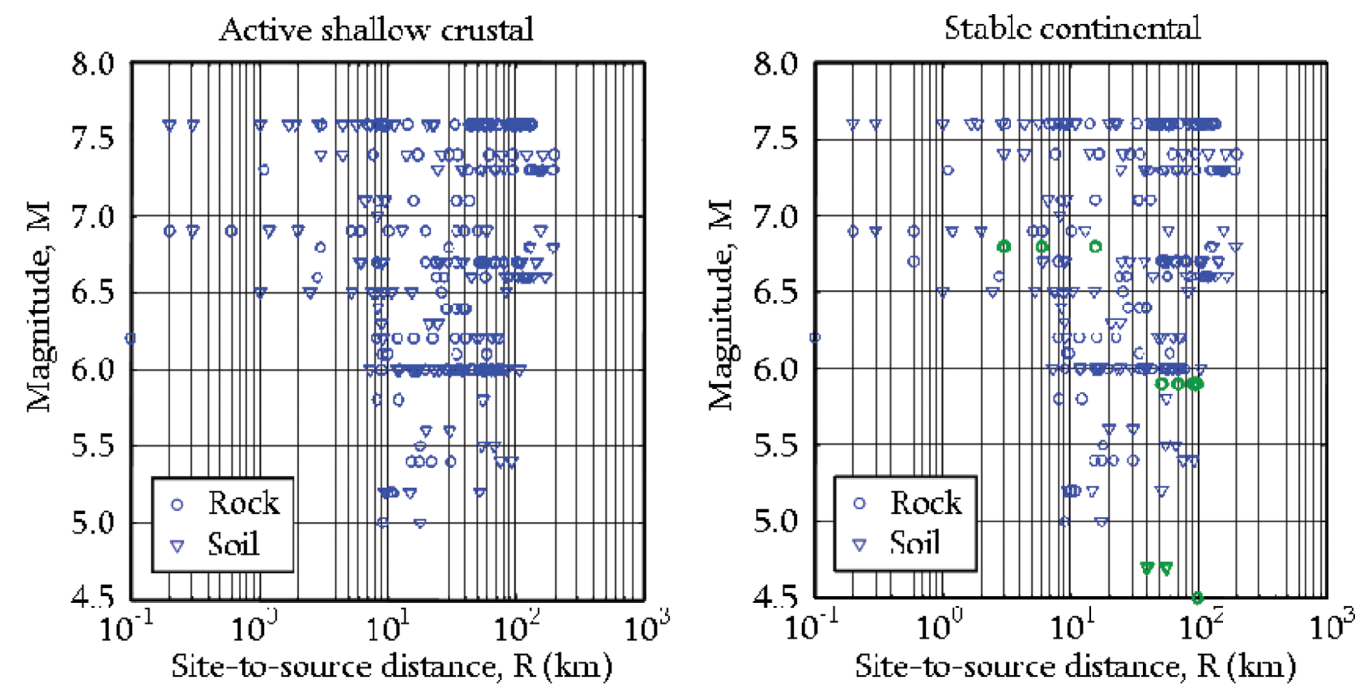

Fig. 2 Earthquake magnitude and site-to-source distance distributions (recorded motions for CENA are shown in bold) 
Table 1 Third letter: geotechnical subsurface characteristics of geomatrix 3-letter site classification

\begin{tabular}{cll}
\hline \hline Third letter & \multicolumn{1}{c}{ Site description } & \multicolumn{1}{c}{ Comments } \\
\hline A & Rock & Instrument on rock $\left(V_{S}>600 \mathrm{~m} / \mathrm{s}\right)$ or $<5 \mathrm{~m}$ of soil over rock. \\
B & Shallow (stiff) soil & Instrument on/in soil profile up to $20 \mathrm{~m}$ thick overlying rock. \\
C & Deep narrow soil & $\begin{array}{l}\text { Instrument on/in soil profile at least } 20 \mathrm{~m} \text { thick overlying rock, in a } \\
\text { narrow canyon or valley no more than several km wide. }\end{array}$ \\
& Deep broad soil & $\begin{array}{l}\text { Instrument on/in soil profile at least } 20 \mathrm{~m} \text { thick overlying rock, in a } \\
\text { broad valley. }\end{array}$ \\
E & Soft deep soil & Instrument on/in deep soil profile with average $\mathrm{V}_{\mathrm{S}}<150 \mathrm{~m} / \mathrm{s}$. \\
\hline
\end{tabular}

applying random vibration theory (RVT) to the model (e.g. Brune 1970, 1971, Boore 1983, McGuire et al. 2001, Silva and Lee 1987). The transfer functions account for the differences in seismic source, wave propagation path properties, and site effects between the WNA and CENA regions. Many seismological publications have shown successful results of the RVT point source model for generating strong ground motions for both WNA and CENA (Boore 1983, 1986, Hanks and McGuire 1981, McGuire et al. 1984, Schneider et al. 1993, Silva 1993). In generating the scaled CENA motions, recorded WNA motions were used as "seed" motions in the spectral scaling process, resulting in scaled motions that have realistic characteristics. In this context, the stochastic point source model is a reliable and reasonable approach for estimating spectral characteristics of strong ground motions for engineering analyses. The scaling method however, should be verified with the next available strong ground motions recorded in CENA.

The ground motions were classified as either "rock" or "soil" based on the site conditions at the respective seismograph stations. The site classification scheme used by McGuire et al. (2001) is based on the third letter of the Geomatrix 3-letter site classification system shown in Table 1. Site categories $\mathrm{A}$ and $\mathrm{B}$ were considered to represent rock sites, and site categories $\mathrm{C}, \mathrm{D}$, and $\mathrm{E}$ were considered to represent soil sites (note that there were only a few motions in the McGuire et al. database that were recorded in category E sites).

\section{Regression analyses}

The non-linear mixed-effects (NLME) regression technique was used to develop the empirical relationships in this study. NLME modeling is a maximum likelihood method based on normal (Gaussian) distribution and is primarily used for analyzing grouped data (i.e. datasets comprised of subsets). The NLME regression method allows regression models to account for both randomeffects that vary from subset to subset and fixed-effects that do not (Pinheiro and Bates 2000). In this study, a subset consists of motions recorded during a given earthquake event. In comparison to applying a fixed-effects regression technique (e.g. the least squares method) to the entire dataset, a mixed-effects regression method allows both inter- and intra-earthquake uncertainty to be quantified. This regression method produces unbiased fittings for each subset having different numbers of ground motion recordings. This is important because of the number of motions from each earthquake can vary significantly. The statistical analysis program $\mathrm{R}$ (version 2.5.0) was used to perform the NLME regression analyses (Lee 2009).

As stated previously, the NLME regression technique inherently assumes the data is normally 
distributed. A quantile-quantile plot (or Q-Q plot) was used to check this assumption (i.e. if the data points plot approximately as a straight line on a normal Q-Q plot, it indicates that the data is normally distributed). As may be observed from the normal Q-Q plot shown in Fig. 3, the entire ground motion duration dataset does not follow a normal distribution. Also, the presence of zeroduration data precludes the data from being log-normally distributed. Furthermore, the zerodurations do not correlate well to the independent variables (e.g. magnitude and site-to-source distance) in the regression analyses.

To circumvent these issues, the zero- and nonzero-duration data were treated separately, with the nonzero-duration data reasonably following a log normal distribution. The total number of nonzero duration data used in the NLME regressions was 568 and 478 for CENA and WNA, respectively; the distributions of zero and nonzero rock and soil motions for CENA and WNA are shown in Fig. 4. The zero-duration data however, needed to be incorporated in the predictive model, otherwise the model would be biased toward longer durations. This is especially true for the duration in WNA due to the considerable number of zero-duration motions, as shown in Fig. 4.

For a given set of moment magnitude, site-to-source distance, and local site condition, the corresponding expected value of duration, $D$ can be expressed using the total probability theorem:

$$
E[D]=E[D \mid D>0] \cdot p(D>0)+E[D \mid D=0] \cdot p(D=0)
$$

where $E[\cdot]$ and $p(\cdot)$ represent expected value and probability, respectively. The second term on the right side of Eq. (1) is zero since the $E[D \mid D=0]$ would be zero. The expected value for $D$, therefore, becomes equal to the quantity of the expected value for a given nonzero-duration (i.e. $E[D \mid D>0])$ times the probability of nonzero-duration occurrence (i.e. $p(D>0)$ ). The NLME regression was performed for modeling the expected value of duration for a given nonzero-duration. A logistic regression method was employed to model the probability of zero-duration occurrence; the probability of nonzero-duration occurrence is determined by subtracting the probability of zero-

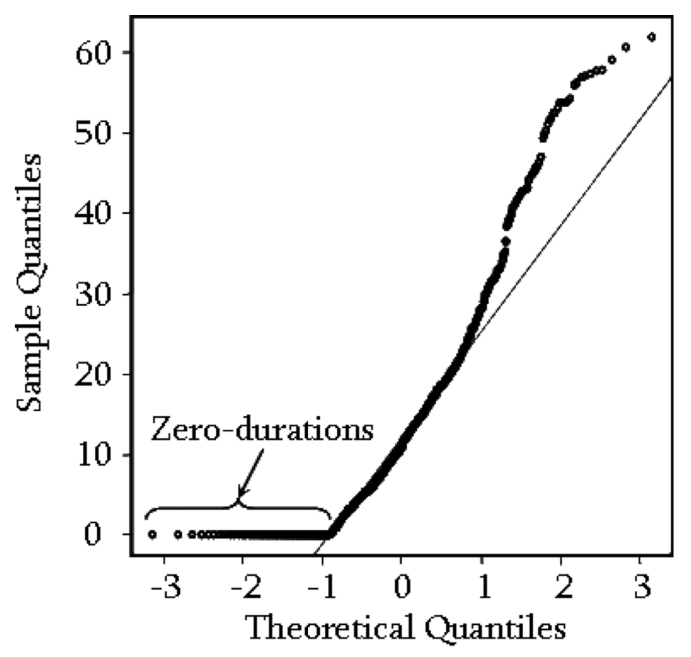

Fig. 3 Normal Q-Q plot of bracketed duration data: WNA rock and soil

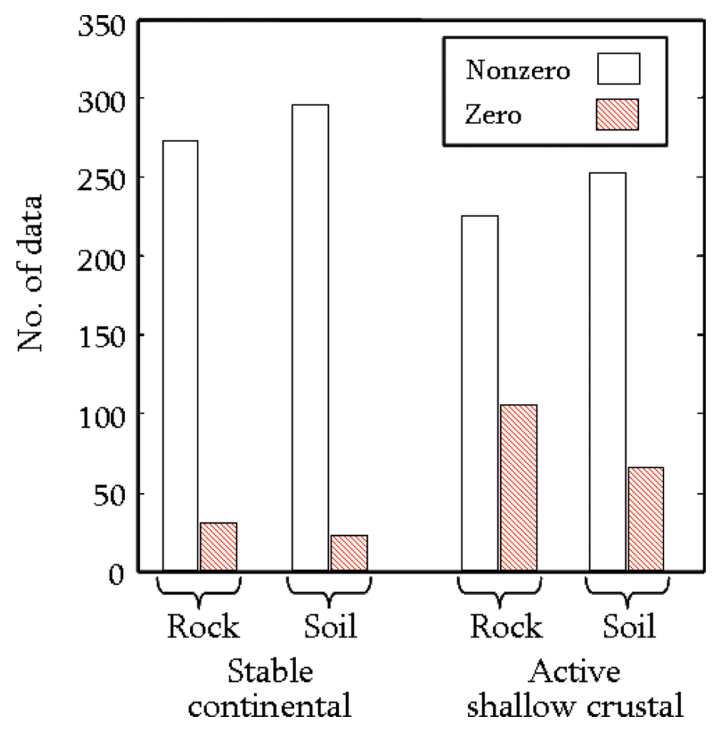

Fig. 4 Zero bracketed duration population 
duration occurrence from 1 . Then, this probability model was applied as a weighting function to the NLME regression result. Both the nonzero and zero duration models were developed as a function of earthquake magnitude, site-to-source distance, and site condition.

\section{Proposed model and regression results}

As discussed above, the proposed model consists of two parts: one is the nonzero duration model that was developed through the NLME regression analyses using nonzero duration data; the other is a weighting function that represents the probability of nonzero duration occurrence for a given earthquake magnitude, site-to-source distance, and site condition, which was developed using logistic regressions.

\subsection{Nonzero duration model}

In assessing the normal distribution of the nonzero duration data, it was found that the data followed a log-normal distribution. Also, adding one second to the durations optimized the overall log-normality of the duration data, as well as the errors. For example, Figs. 5 and 6 show the
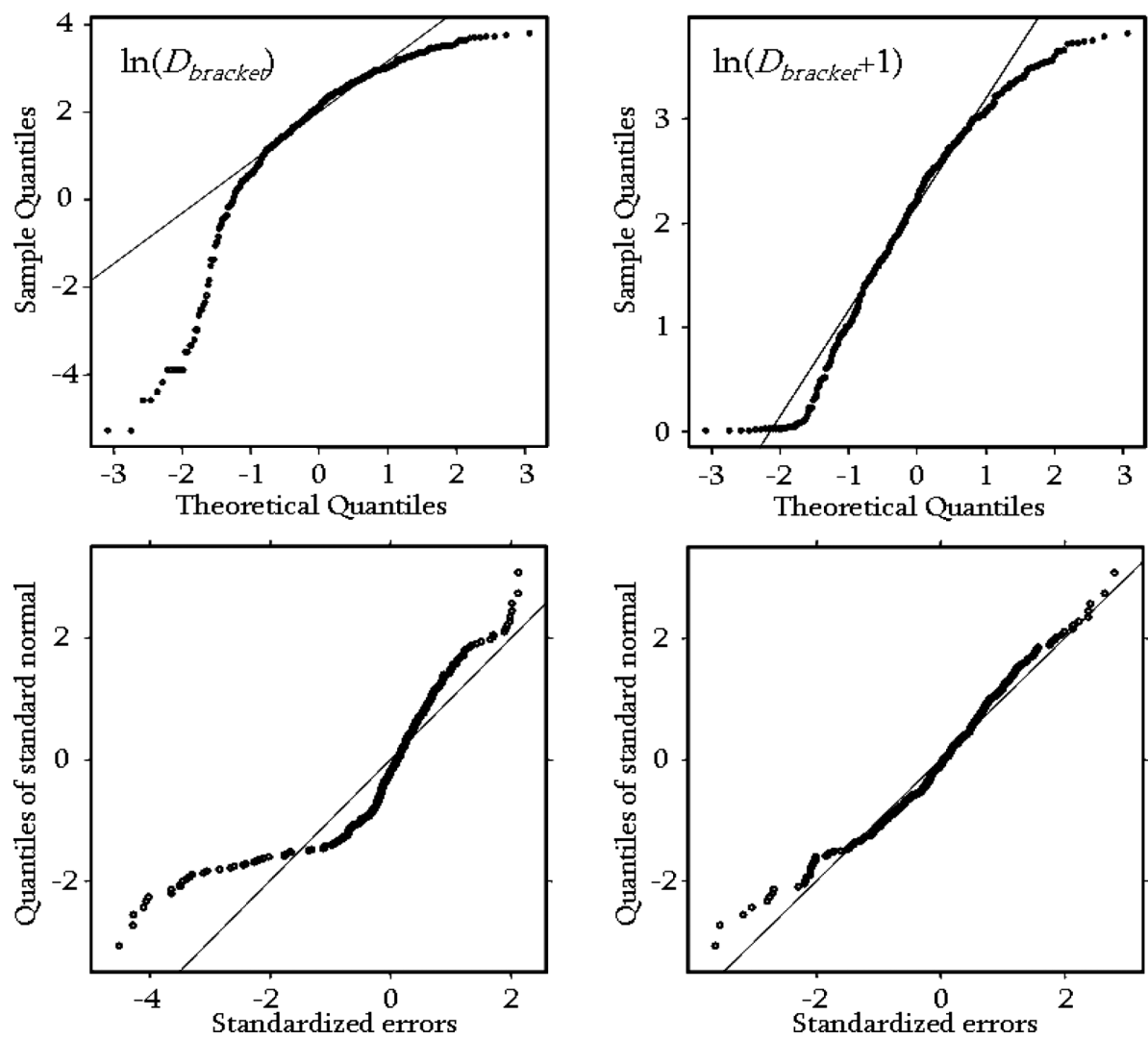

Fig. 5 Comparisons of normal Q-Q plots for $\ln \left(D_{\text {bracket }}\right)$ (left) and $\ln \left(D_{\text {bracket }}+1\right)$ (right) and the errors resulted (bottom): WNA rock and soil 
improvement in the log-normal distributions of the bracketed duration data and errors for WNA and CENA, respectively. As may be observed from this figure, $\ln \left(D_{\text {bracket }}+1\right)$ more closely follows a normal distribution than $\ln \left(D_{\text {bracket }}\right)$. Again, this optimization of the normality is necessary because normal distribution of data and errors is inherently assumed in the theoretical formulation of the NLME regression. Accordingly, the NLME regression analyses were performed on $\ln \left(D_{\text {bracket }}+1\right)$.

Developing functional forms of the predictive model was achieved through "trial and error", where the model selection was based on the standard error/deviation (i.e. the smallest) and the correct representation of the underlying physics. After considering numerous functional forms of the predictive relationship in the NLME regressions, the model that gave the best fit (i.e. the smallest standard deviation) of both the WNA and CENA nonzero duration data is

$$
E\left[D_{\text {bracket }} \mid D_{\text {bracket }}>0\right]=\exp \left(C_{1}+C_{2}\left(M_{W}-6\right)+C_{3} R+\left(S_{1}+S_{2} R\right) S_{S}\right)-1 \geq 0
$$

where: $E\left[D_{\text {bracket }} \mid D_{\text {bracket }}>0\right]$ is the expected value of bracketed duration $(s)$ for a given $D_{\text {bracket }}$ greater than zero (i.e. nonzero bracketed duration); $C_{1}$ through $C_{3}, S_{1}$, and $S_{2}$ are regression coefficients; $M_{W}$ is moment magnitude; $R$ is the closest distance to the fault rupture plane $(\mathrm{km})$; and $S_{S}$ is a binary number representing local site conditions: $S_{S}=0$ for rock sites, $S_{S}=1$ for soil sites. Note
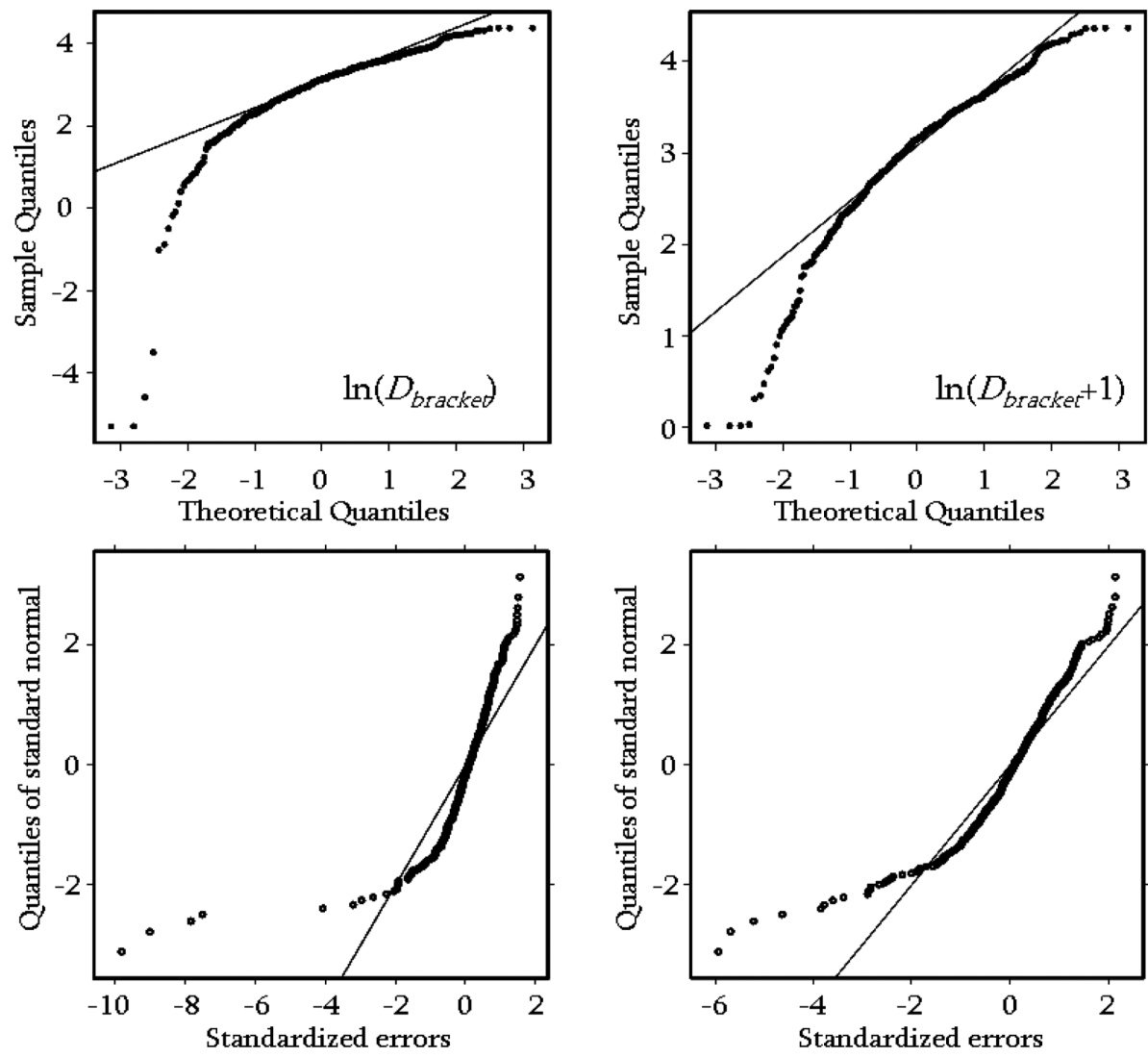

Fig. 6 Comparisons of normal Q-Q plots for $\ln \left(D_{\text {bracket }}\right)$ (left) and $\ln \left(D_{\text {bracket }}+1\right)$ (right) and the errors resulted (bottom): CENA rock and soil 
Table 2 NLME Regression results: regression coefficients and standard deviations

\begin{tabular}{lcccccc}
\hline \hline & $C_{1}$ & $C_{2}$ & $C_{3}$ & $S_{1}$ & $S_{2}$ & $\sigma_{l n}^{\dagger}$ \\
\hline Stable continental & 2.67 & 0.75 & -0.0058 & -0.16 & 0.0021 & 0.67 \\
Active shallow crustal & 2.04 & 0.95 & -0.022 & 0.074 & 0.0045 & 0.65 \\
\hline
\end{tabular}

${ }^{\dagger}$ The standard deviation values are for $\ln \left(D_{\text {bracket }}+1\right)$

that the proposed model given by Eq. (2) was rewritten from its original form by taking the exponential and subtracting 1 from both sides of the original equation, i.e.: $D_{\text {bracket }}=\exp \left[\ln \left(D_{\text {bracket }}+1\right)\right]-1$. It is also noted that if a bracketed duration obtained from Eq. (2) is less than zero, zero should be used as the predicted duration. The results from the NLME regression analyses of the nonzero duration data are shown in Table 2.

\subsection{Combined model with weighting function}

To estimate the probability of the occurrence of a zero-duration motion, logistic regressions were implemented separately for each tectonic regime and site condition, as a function of $M$ and $R$. The logistic function is defined as

$$
p\left(D_{\text {bracket }}=0 \mid M_{W}, R\right)=\frac{e^{\beta_{1}+\beta_{2} M_{W}+\beta_{3} R}}{1+e^{\beta_{1}+\beta_{2} M_{W}+\beta_{3} R}}
$$

where $p\left(D_{\text {bracket }}=0 \mid M_{W}, R\right)$ is the probability of zero-duration for a given $M_{W}$ and $R ; \beta_{1}$ through $\beta_{3}$ are the regression coefficients determined from separate logistic regressions for each site condition of CENA and WNA. Then, the probability of the duration being greater than zero is one minus the probability of that it is zero-duration

$$
p\left(D_{\text {bracket }}>0 \mid M_{W}, R\right)=1-p\left(D_{\text {bracket }}=0 \mid M_{W}, R\right)=\frac{1}{1+e^{\beta_{1}+\beta_{2} M_{W}+\beta_{3} R}}
$$

The results of logistic regression are shown in Table 3. Also, the resulting weighting functions for different magnitudes, site-to-source distances, and site conditions are shown in Fig. 7.

Eq. (4), in conjunction with the regression coefficients for a given site condition and tectonic setting, is used as the weighting function that is multiplied with Eq. (2). The combined model proposed for horizontal durations that account for zero-durations is given by

$$
E\left[D_{\text {bracket }}\right]=\left\{\exp \left(C_{1}+C_{2}\left(M_{W}-6\right)+C_{3} R+\left(S_{1}+S_{2} R\right) S_{S}\right)-1\right\} \cdot p\left(D_{\text {bracket }}>0 \mid M_{W}, R\right) \geq 0
$$

Table 3 Logistic regression coefficients for weighting functions

\begin{tabular}{lcccc}
\hline \hline & Site & $\beta_{1}$ & $\beta_{2}$ & $\beta_{3}$ \\
\hline Stable continental & Rock & 9.47 & -2.28 & 0.042 \\
& Soil & 4.19 & -1.32 & 0.025 \\
Active shallow crustal & Rock & 4.11 & -1.24 & 0.058 \\
& Soil & -0.39 & -0.56 & 0.039 \\
\hline
\end{tabular}



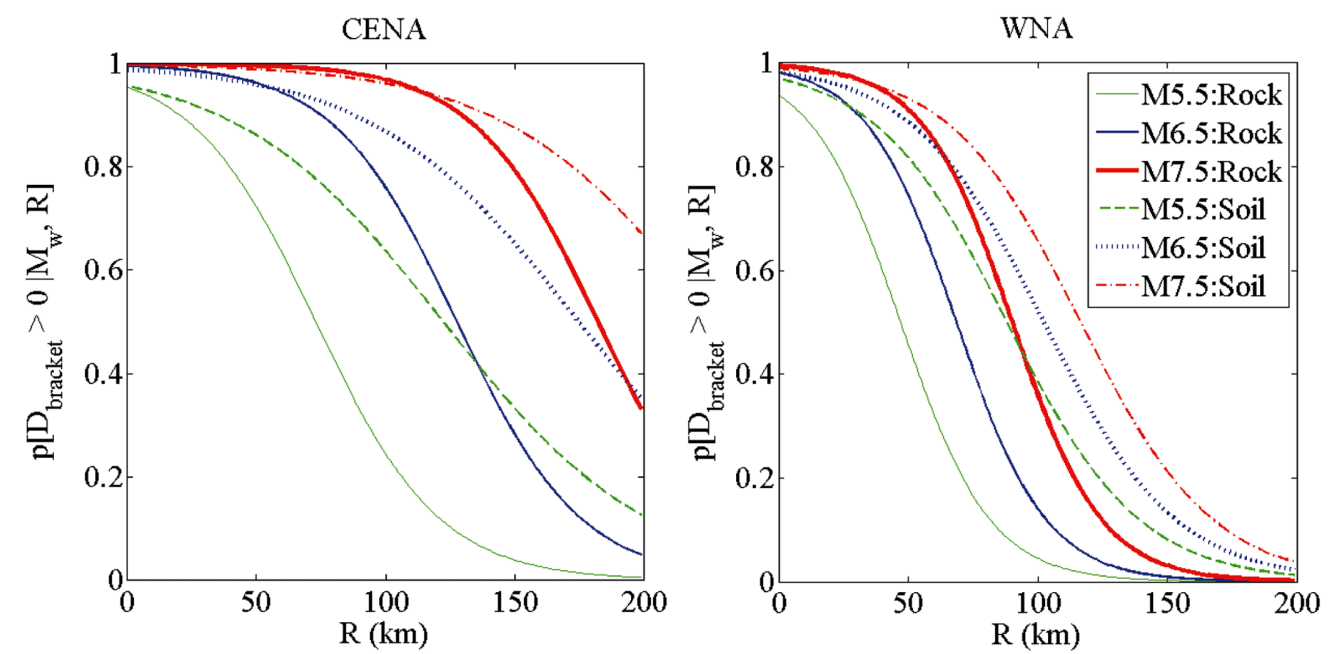

Fig. 7 Probability of the duration being greater than zero for different magnitudes, site-to-source distances, and site conditions
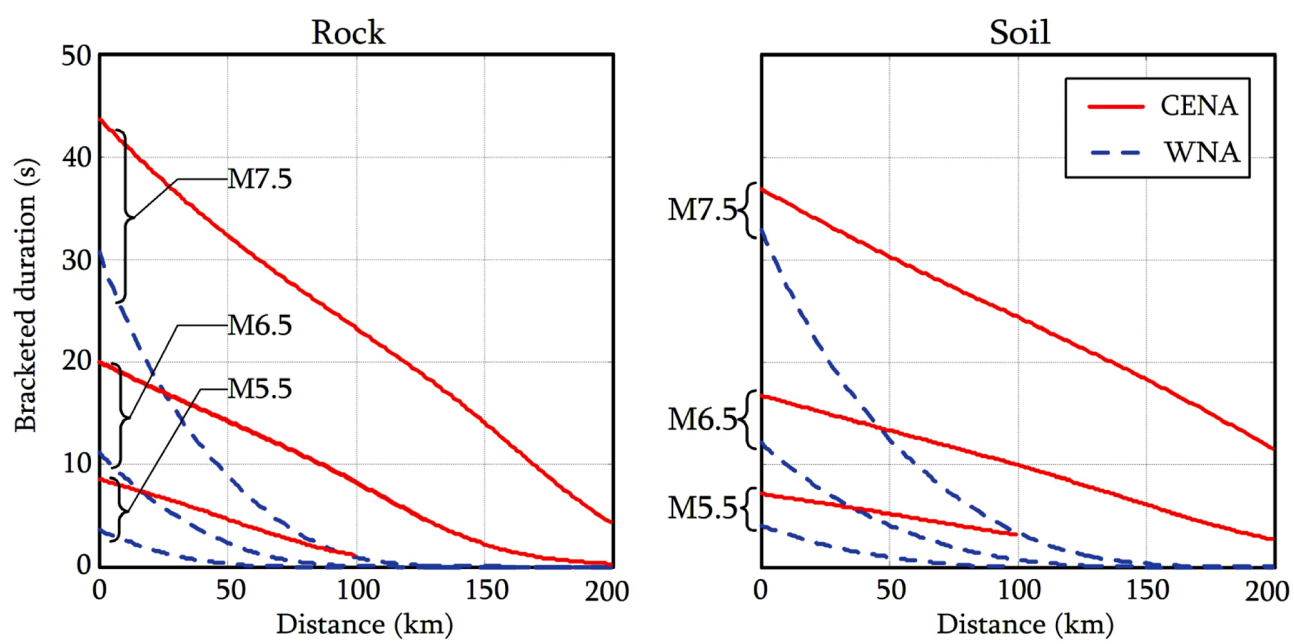

Fig. 8 Comparisons of CENA and WNA median bracketed durations predicted by the combined model (Eq. (5))

Using Eq. (5), in conjunction with the coefficients listed in Tables 2 and 3, the median bracketed durations predicted for CENA and WNA are shown in Fig. 8. For both CENA and WNA, the bracketed durations decrease with increasing distance, but increase with increasing magnitude. As may be observed, the duration varies significantly with magnitude, especially at distances less than $50 \mathrm{~km}$ where an increase in one magnitude unit results in at least a twofold increase in duration. For both rock and soil sites, CENA motions consistently have longer durations than WNA motions. Also, it is clearly seen that as distance increases, WNA durations tend to decrease at a faster rate than CENA durations. This observation is consistent with the current seismological understanding of the characteristic difference between CENA and WNA ground motions (e.g. Atkinson and Boore 1995). Consequently, CENA motions have significantly longer durations than WNA motions at 

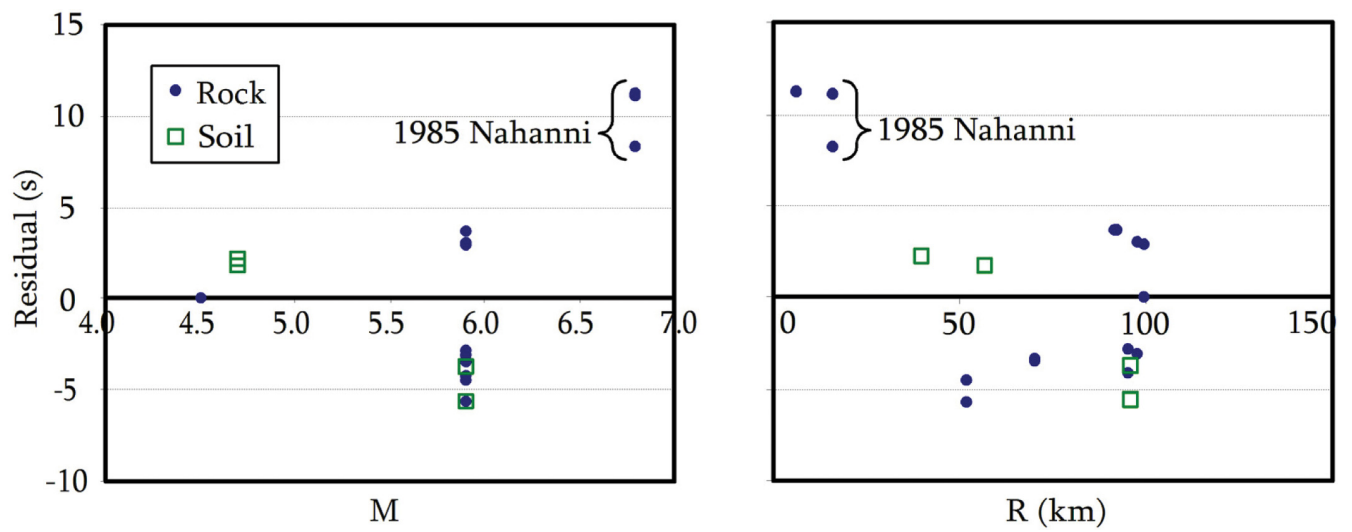

Fig. 9 Residuals for CENA recorded motions from the 1988 Saguenay, 1985 Nahanni, 1989 New Madrid earthquakes

greater distances. In comparing CENA rock and soil motions, soil motions appear to have shorter bracketed durations than rock motions at distances less than about $75 \mathrm{~km}$. This contradicts the trend shown for the WNA motions. This conflicting trend may be attributed to relatively rich highfrequency content of CENA motions. That is, high-frequencies in CENA motions filter out as the motions propagate up through soil layers. Also, ground motions close to the fault rupture (i.e. less than about $50 \mathrm{~km}$ ) are richer in high-frequencies than those at longer distances because highfrequency waves tend to decay as they propagate farther from the source.

The residuals (i.e. predicted median - actual value) for the 28 recorded ground motions for CENA are shown in Fig. 9 as functions of magnitude and distance. As may be observed from this figure, with the exception of the 1985 Nahanni (Canada) ground motions (S1010, S1280, S3270, and S3360), the residuals are within about $+/-5$ seconds, indicating that the model predictions are in general accord with the limited available recorded motions.

It is again noted that the objective of the study presented herein is the development of a predictive relationship for the bracketed duration for CENA ground motions. The primary reason for developing the relationship for WNA motions was to allow comparisons to be made of the motion durations from the two different tectonic settings using consistently developed relationships. While the WNA bracketed duration relationship presented herein is completely valid, the authors would have included the influence of factors such as fault mechanism, basin effects, hanging wall vs. foot wall, more refined site classifications, etc. if their objective were to develop a relationship for WNA. However, because many of these factors are not discernable for most CENA motions and sites, they were not considered in developing either the CENA or WNA relationships in the present study.

\subsection{Comparison with existing relationships}

The bracketed duration relation proposed in this study is compared with the relationships proposed by Chang and Krinitzsky (1977) and Bommer et al. (2009). Chang and Krinitzsky determined upper bounds of the bracketed durations for rock data and soil data from a limited ground motion dataset of 201 horizontal ground motions from 25 WNA earthquakes, mostly from the 1971 San Fernando earthquake (M6.6). Chang and Krinitzsky (1977) did not give details on 
how they performed their regression analyses. However, they linearly-extrapolated and/or interpolated their relationship developed from magnitude and distance ranges where data was available to ranges for which little-to-no data was available. Also, they truncated the durations for far field soil sites, based on zero-durations observed from the duration data from the 1952 Kern county earthquake (M7.7). In contrast to Chang and Krinitzsky (1977), the Bommer et al. (2009) relationship was developed using the NLME regression method on the records from the Next Generation of Attenuation (NGA) global database. Also, Bommer et al. (2009) attempted to take into account the zero-durations by modeling duration data as a semi-continuous censored lognormally distributed random variable (Stafford 2008). Fig. 10 shows the comparison of the bracketed duration relations. Considerable differences exist between the WNA predictions from this study and from Chang and Krinitzsky (1977), except for the predictions for M7.5 for WNA rock sites. Overall, Chang and Krinitzsky model predicts significantly longer durations than this study's WNA model, especially for soil sites. This is likely due to Chang and Krinitzsky (1977) using upper-bound durations and not fully accounting for zero-duration motions. On the other hand, the WNA predictions by this study and Bommer et al. (2009) are in relatively good agreement for small-to-intermediate magnitudes (e.g. M5.5 and M6.5). The WNA predictions for large magnitudes (e.g. M7.5), however, significantly differ between the two studies at distances less than about $20 \mathrm{~km}$. This might be a result of the differences in the number of large-magnitude motions in the
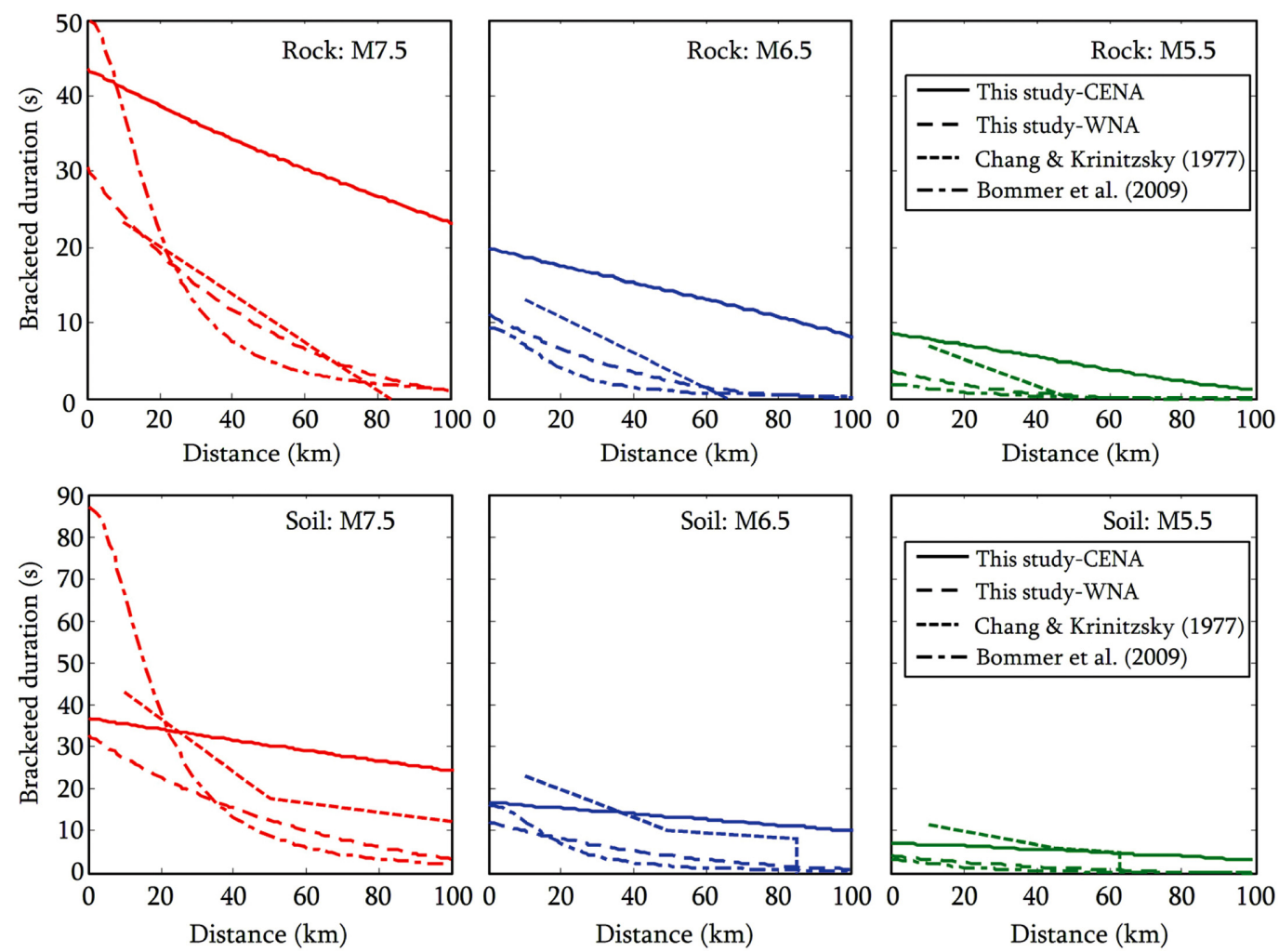

Fig. 10 Comparison of predicted bracketed durations by this study, Chang and Krinitzsky (1977), and Bommer et al. (2009), $V_{S 30}=600 \mathrm{~m} / \mathrm{s}$ and $300 \mathrm{~m} / \mathrm{s}$ were used for the Bommer et al. (2009) relationship for rock and soil sites, respectively 
databases used in the two studies, as the same regression method (i.e. NLME) was used in the studies. In comparing the CENA relationship proposed herein with existing WNA relationships, the CENA motions consistently have longer bracketed durations than WNA motions for large magnitudes at distances greater than about $50 \mathrm{~km}$. This is expected because WNA motions, in general, attenuate more rapidly with distance than CENA motions.

\section{Conclusions}

An empirical predictive relationship for bracketed duration of horizontal strong ground motions in CENA has been proposed herein. Zero-durations were incorporated into the model through weighting functions representing the probability of nonzero duration. The bracketed durations were predicted to decrease with increasing distance, but to increase significantly with increasing magnitude. Comparing CENA and WNA motions, CENA rock and soil motions consistently have longer durations than WNA motions. This same trend holds when comparing this study's CENA predicted durations at distances greater than about $50 \mathrm{~km}$ with those predicted for WNA using existing relationships. Also, WNA durations tend to attenuate at a faster rate as a function of distance than CENA durations. This results in larger differences in the durations of the WNA and CENA motions at greater distances. Lastly, the scaling method used to generate the CENA motions used in this study (McGuire et al. 2001) should be further verified as new CENA recorded motions become available, as well as verifying other proposed scaling methods (e.g. Campbell 2003).

\section{Acknowledgments}

This material is based upon work supported in part by the National Science Foundation under Grant Nos. CMMI 0962952 and 1030564. This support is gratefully acknowledged. However, any opinions, findings, and conclusions or recommendations expressed in this material are those of the authors and do not necessarily reflect the views of the National Science Foundation.

\section{References}

Atkinson, G.M. and Boore, D.M. (1995), "Ground-motion relations for eastern North America", B. Seismol. Soc. Am., 85(1), 17-30.

Bolt, B.A. (1973), "Duration of strong ground motions", Fifth World Conference on Earthquake Engineering, Rome, 1304-1313.

Bommer, J.J. and Martinez-Pereira, A. (1999), "The effective duration of earthquake strong motion", J. Earthq. Eng., 3(2), 127-172.

Bommer, J.J., Stafford, P.J. and Alarcon, J.E. (2009), "Empirical equations for the prediction of the significant, bracketed, and uniform duration of earthquake ground motion", B. Seismol. Soc. Am., 99(6), 3217-3233.

Boore, D.M. (1983), "Stochastic simulation of high-frequency ground motions based on seismological models of the radiated spectra", B. Seismol. Soc. Am., 73(6A), 1865-1894.

Boore, D.M. (1986), "Short-period P- and S-wave radiation from large earthquakes: implications for spectral scaling relations", B. Seismol. Soc. Am., 76(1), 43-64.

Boore, D.M. and Joyner, W.B. (1984), "A note on the use of random vibration theory to predict peak amplitudes of transient signals”, B. Seismol. Soc. Am., 74(5), 2035-2039. 
Brune, J.N. (1970), "Tectonic stress and spectra of seismic shear waves from earthquakes", J. Geophys. Res., 75(26), 611-614.

Brune, J.N. (1971), “Correction”, J. Geophys. Res., 76(20), 1441-1450.

Campbell, K. (2003), "Prediction of strong ground motion using the hybrid empirical method and its use in the development of ground-motion (attenuation) relations in Eastern North America', B. Seismol. Soc. Am., 93(3), 1012-1033.

Chang, F.K. and Krinitzsky, E.L. (1977), "State-of-the-art for assessing earthquake hazards in the united states. Report 8. Duration, Spectral Content, and Predominant Period of Strong Motion Earthquake Records from Western United States", United States.

Hanks, T.C. and McGuire, R.K. (1981), "The character of high-frequency strong ground motion", B. Seismol. Soc. Am., 71(6), 2071-2095.

Hays, W.W. (1975), "A note on the duration of earthquake and nuclear-explosion ground motions", B. Seismol. Soc. Am., 65(4), 875-883.

Lee, J. (2009), "Engineering characterization of earthquake ground motions", Ph.D. Dissertation, University of Michigan, Ann Arbor.

McGuire, R.K., Becker, A.M. and Donovan, N.C. (1984), "Spectral estimates of seismic shear waves", Bull. Seismol. Soc. Am., 74(4), 1427-1440.

McGuire, R.K., Silva, W.J. and Costantino, C.J. (2001), "Technical basis for revision of regulatory guidance on design ground motions: hazard-and risk-consistent ground motion spectra guidelines", US Nuclear Regulatory Commission, Washington, DC.

Page, R.A., Boore, D.M., Joyner, W.B. and Coulter, H.W. (1972), Ground motion values for use in seismic design of the trans-Alaska pipeline system, US Geological Survey Circular 672.

Pinheiro, J.C. and Bates, D.M. (2000), Mixed-effects models in S and S-PLUS, Springer, New York.

Program-R. (version 2.5.0), "A language and environment for statistical computing and graphics: http://www.rproject.org/"

Schneider, J.F., Silva, W.J. and Stark, C. (1993), "Ground motion model for the 1989 M 6.9 loma prieta earthquake including effects of source, path, and site", Earthq. Spectra, 9(2), 251-287.

Silva, W.J. (1993), "Factors controlling strong ground motion and their associated uncertainties", Dynamic Analysis and Design Considerations for High-Level Nuclear Waste Repositories, San Francisco, CA, USA, 132-161.

Silva, W.J. and Lee, K. (1987), "WES RASCAL code for synthesizing earthquake ground motions: state-of-theart for assessing earthquake hazards in the United States", Report 24, US Army Engineering Waterways Experiment Station Vicksburg, MS.

Stafford, P.J. (2008), “Conditional prediction of absolute durations”, B. Seismol. Soc. Am., 98(3), 1588-1594.

$J L$ 


\section{Appendix. Scaling procedure for CENA motions}

The scaling procedure used by McGuire et al. (2001) consists of the following computation processes: (1) determination of response spectral transfer function, (2) computation of response spectrum for a given ground motion, (3) determination of target response spectrum, and (4) spectral matching of the time history. A response spectral transfer function was obtained by first using the single-corner frequency point source model (Brune 1970, 1971) to compute smoothed Fourier amplitude spectra (FAS) for both the CENA and WNA. The values of the point source model parameters used are listed in Table A1, where $\kappa$ is a parameter that represents damping in the shallow crust directly below the site; $\Delta \sigma$ represents the stress drop at the source; $Q_{0}$ and $n$ are regional dependent parameters for the frequency dependent quality factor, $Q(f) ; \rho_{0}$ is crustal density in the source region; and $\beta_{0}$ is shear wave velocity of the crust at the source. Next, random vibration theory (RVT) was used to generate response spectra from the FAS (e.g. Boore 1983, Boore and Joyner 1984, Silva and Lee 1987). The ratio of these two response spectra is the spectral transfer function. The response spectral transfer functions were generated for each site condition; horizontal/vertical component; earthquake magnitudes of 5.5, 6.5 and 7.5 (i.e. center value of magnitude bins); and distances of 1, 5, 30, 75, and $130 \mathrm{~km}$. A total 60 different transfer functions were therefore developed. Example transfer functions for M6.5 cases are shown in Fig. A1. The response spectrum (5\% damping) of a WNA "seed" acceleration time history is then computed. Next, the CENA target response spectrum is obtained by multiplying the "seed" motion's response spectrum by the appropriate response spectral transfer function. Lastly, the "seed" acceleration time history is scaled to match the target CENA response spectrum (Silva and Lee 1987). In the spectral matching process, a sample time interval $\Delta t$ of $0.005 \mathrm{sec}$ (the corresponding Nyquist frequency is $100 \mathrm{~Hz}$ ) was used to avoid aliasing effects in the frequency range of interest.

Table A1 Point source parameters for WNA and CENA motions (McGuire et al. 2001)

\begin{tabular}{ccc}
\hline \hline & WNA & CENA \\
\hline$\Delta \sigma($ bars $)$ & 65 & 120 \\
$\kappa(\mathrm{sec})$ & 0.040 & 0.006 \\
$Q_{0}$ & 220 & 351 \\
$n$ & 0.60 & 0.84 \\
$\beta_{0}(\mathrm{~km} / \mathrm{sec})$ & 3.50 & 3.52 \\
$\rho_{0}\left(\mathrm{gm} / \mathrm{cm}^{3}\right)$ & 2.70 & 2.60 \\
\hline
\end{tabular}



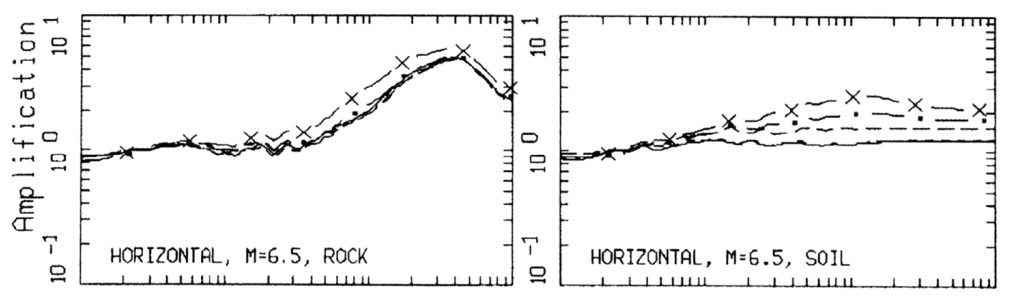

WUS TO CEUS TRANSFER FUNCTIONS

FOR 5\% DAMPING RESPONSE SPECTRA

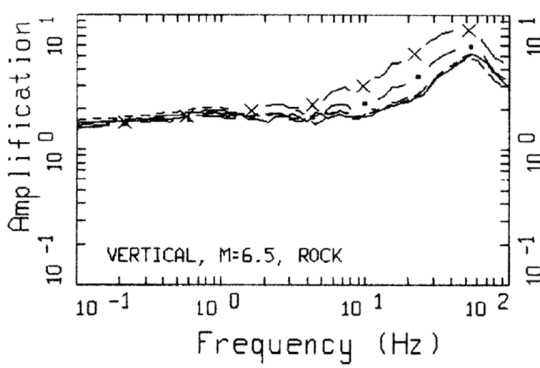

LEGEND

$\longrightarrow \quad D=1 \mathrm{kM}$

$D=5 \mathrm{kM}$

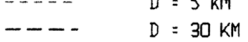

$\begin{array}{ll}-- & D=75 \mathrm{kM} \\ -\times- & D=130 \mathrm{kM}\end{array}$

Fig. A1 Response spectral transfer functions for M6.5, rock and soil sites, horizontal and vertical components, and each distance cases (from McGuire et al. 2001) 